At the same time, we will see many universities and their faculty and students in the United States and in Europe resist these trends and take initiatives to promote international solidarity, cooperation, and exchanges. Global citizenship, a concept denied by Trump and May, will become a key factor in the fight of universities for autonomy and academic freedom. The reactions of academic leaders, faculty, and students in US universities and colleges to the restrictions imposed by the Trump administration, are a clear manifestation of their opposition. These reactions are not driven by a fear of losing revenue, but by their attachment to the core values of higher education.

DOI: http://dx.doi/org/Io.6oI7/ihe.20I7.89.9758

\section{Academic Staff Mobility in the Age of Trump and Brexit?}

\section{LiUdvika Leisyte and Anna-Lena Rose}

Liudvika Leisyte is professor of higher education, and Anna-Lena Rose is research and teaching assistant and doctoral student at the Center for Higher Education, Technical University of Dortmund, Germany. E-mail: liudvika.leisyte@tu-dortmund.de; anna-lena.rose@tu-dortmund.de.

\begin{abstract}
A cademic mobility and the attractiveness of higher education systems are increasingly associated with excellence, the creation of dynamic, international networks, enhanced scientific performance, improved knowledge and technology transfer, and ultimately improved economic and social welfare. The success of higher education institutions, measured in terms of high-quality teaching and research output and the attraction of large research grants, is strongly influenced by the academic staff they employ. In times of growing international competition, the ability to attract talented academic staff is the key ingredient of success for universities and economies worldwide. Yet, current political developments, characterized by increasing populism, nationalist tendencies, and strong anti-immigration discourses might lead to significant shifts in traditional patterns of international academic staff mobility.
\end{abstract}

Traditional Mobility Patterns

Austria and the United Kingdom (where 25 percent of aca- demic staff are foreign nationals), Denmark, Ireland, the Netherlands, and Norway (30 percent), Luxembourg and Switzerland (more than 50 percent) are the European countries that have attracted most foreign academic talent in Europe up to now. The 2016 Science and Engineering Indicators show that in the United States, more than half of the postdoctoral workforce is foreign born. Existing patterns of academic mobility do, however, tend to reinforce inequalities between academic centers such as those mentioned above and academic peripheries (to speak in Altbach's terms), which are usually located in smaller, geographically remote, and economically weaker countries, and constitute less attractive destinations for international academic staff. Traditional losers of the brain-gain and brain-drain dynamics of international academic staff mobility include Central and Eastern European (CEE), South European, Latin American, and some Asian countries, as well as many developing countries across the world.

Our recent study of patterns of academic staff mobility in CEE countries-Estonia, the Czech Republic, and Lithuania (traditionally closed systems characterized by transition economies, distinctive cultures and histories, and protectionism of their national languages) has revealed that these countries struggle both to retain and to attract academic talent, resulting in predominantly outbound mobil-

Estonia stands out as a best-practice
example in implementing concrete poli-
cies and imposing clear targets at both
national and institutional levels for
opening recruitment and attracting for-
eign academic talent.

ity flows. Key barriers to attracting talented academic staff from abroad include comparatively low salary levels, a lack of transparency in recruitment and promotion procedures, high degrees of nepotism and academic inbreeding, as well as a lack of foreign language competencies among older generations of local academic staff. In the Baltic States, especially in Latvia, further barriers are created by local language requirements for foreign academic staff. We observed that academics moving to CEE countries seem to be motivated by factors that differ from those moving to other countries in the world. Instead of career progression, access to knowledge and equipment, autonomy and academic freedom, and lower teaching loads and more time for research, 
interview partners noted personal ties and family-related factors, or a specific interest in the history, language, and culture of the host country, as their primary motivations.

Although recent policy rhetoric points to the imperative of attracting academic talent from abroad, concrete measures are lacking and problems with legal salary schemes and legal frameworks for immigration remain largely unsolved. At the same time, we observe that CEE countries have significantly improved their research infrastructure with investments from EU structural funds. Moreover, higher education institutions in CEE countries are increasingly offering courses and programs in foreign languages, usually English, which facilitates the participation of foreign academic staff in educational activities. Additionally, a growing number of individual institutions in CEE countries that struggle to attract international academic staff on a regular employment basis engage in alternative strategies, such as public-private partnerships, which are more attractive to international academic staff due to better remuneration and more time for research activities.

\section{Brexit and Trump: Changing the Rules of the Game?}

Increasing populism, nationalist tendencies, and strong public anti-immigration discourses can currently be witnessed in many countries worldwide, and the question of attracting and retaining academic talent to ensure the competitiveness of science and higher education systems in Europe and the United States remains paramount. Especially in light of events such as the 2016 referendum in favor of what is commonly referred to as "Brexit" (the United Kingdom leaving the European Union), and the immigration policy proposed by President Trump in the United States, we assume that the number of academics moving to both countries will decrease. Furthermore, recent reports from the United Kingdom reveal that academics from EU countries have been told by the Home Office to make arrangements to leave the country. As motivations and possibilities for foreign academics to move to and stay in these countries decrease, will this lead to new opportunities for other countries to increase their talent base?

Due to demographic downturn, increased emigration rates, especially of young people, and an aging academic workforce, attracting foreign students and academic staff will become an ever more important aspect to ensure the competitiveness and ultimately the survival of higher education systems in CEE countries. We expect increasing awareness of the importance of changing national and institutional practices and legal frameworks in order to attract international academic staff. Among CEE countries, Estonia stands out as a best-practice example in implementing concrete policies and imposing clear targets at both na- tional and institutional levels for opening recruitment and attracting foreign academic talent. From EU accession in 2004 to 20I4, the share of foreign academic staff in Estonia has increased almost eight-fold, to more than 8 percent. Recently, increased efforts to advertise in Science and openly recruit top scientists with significant investments can also be observed in Poland, and we expect other CEE countries to follow this example in the future.

As conditions for recruiting and retaining foreign academic talent are changing in countries like the United Kingdom and the United States, new windows of opportunity may open up for Central and Eastern Europe and other countries previously located at the peripheries of higher education. Provided that these countries do not follow the trend towards increasing national isolation, and anticipating that they will follow positive examples in their regions of decreasing barriers for incoming mobility, they might be able to increase significantly the attractiveness of their systems for talented academics from abroad. In such instances, we may witness a significant change of direction in international academic mobility trends.

\section{DOI: http://dx.doi/org/ıo.6oI7/ihe.20I7.89.976I}

\section{Do Rankings Drive Better Performance?}

\section{SiMON MARGINSON}

Simon Marginson is professor of international higher education, Institute of Education, University College London, and director, ESRC/ HEFCE Centre for Global Higher Education. E-mail: s.marginson@ ucl.ac.uk.

$\mathrm{G}$ lobal ranking is still only I3 years old, but has already Tinstalled itself as a permanent part of international higher education; it has deeply transformed the sector. Global ranking is inevitable. People inside and outside the sector want to understand higher education, and ranking is the simplest way to do so. It maps the pecking order and underpins partnership strategies. It guides investors in research capacity. It shapes the life decisions of many thousands of cross-border students and faculty-despite the patchy quality of much of the data, and the perverse effects of all rankings, good or bad.

Global ranking has remade global higher education as a relational environment, magnifying some potentials 